\section{Keeping people with MS in the workforce through effective treatment}

\author{
Steve Simpson, Jr. (i) ${ }^{1,2}$
}

\section{Data linkage shows that effective disease-modifying therapy keeps patients in paid work and off disability pension}

The clinical pathogenesis of multiple sclerosis (MS) can be profoundly deleterious to employment, with disability and fatigue leading to reduced employment hours, changes to less demanding job tasks, and early retirement. ${ }^{1}$ Given the typical onset of MS in the 20-40 years old range, these effects on employment occur in the prime years when people are typically establishing their careers. MS clinical progression leads directly to reduced or lost income and forced patients to rely on disability pension supports, and thus becoming a significant cost for society. Until recently, treatment options to reduce MS progression were limited. Symptom-specific treatments could ameliorate some elements like spasticity, incontinence and fatigue but did nothing to target the underlying neuropathology. First-generation immunomodulatory therapies like interferonbeta are effective at reducing relapse rates in some patients but not all, and their side effect profiles and development of treatment resistance are such that treatment may only be maintained for a handful of years. ${ }^{2}$ Second-generation immunomodulatory medications, however, particularly the monoclonal antibody-based medications like alemtuzumab, natalizumab, and ocrelizumab, and oral medications like fingolimod and dimethyl fumarate, have much greater clinical efficacy than their first-generation predecessors, have fewer

${ }^{1}$ Neuroepidemiology Unit, Melbourne School of Population \& Global Health, The University of Melbourne, Melbourne, Victoria, Australia ${ }^{2}$ Menzies Institute for Medical Research, University of Tasmania, Hobart, Tasmania, Australia

Correspondence to Dr Steve Simpson, Jr., Neuroepidemiology Unit, Melbourne School of Population \& Global Health, The University of Melbourne, Carlton, VIC, Australia; steve.simpson@ unimelb.edu.au side effects, and easier modes of administration which enhance treatment adherence. ${ }^{3}$ These features taken together make the possibility of a complete lack of clinical activity, namely no relapses or disability progression, known as No Evidence of Disease Activity (NEDA) a reality, and thus the potential retention of people with MS in employment a possibility as well.

It is the impact of NEDA on employment outcomes, specifically loss of employment and moving onto disability pension, which Chalmer and colleagues ${ }^{4}$ have investigated in this issue of JNNP. They leveraged the remarkable power of the data linkage systems available in Denmark and other Scandinavian countries, combining clinical and treatment data from the national Danish MS Register with income and pension data collected by Statistics Denmark, including the income statistics register and the DREAM database. With these, they comprehensively examined the interplay between patients' treatments and clinical progression with their change in income and pension usage in 3123 and 2406 patients for the income loss and pension risk, respectively, over a median follow-up of 4.9 years. Their income among NEDA patients compared with those with clinical activity and 57\% reduction in risk of starting disability pension, are demonstrative of the positive impacts of effective treatment in MS on employment and income outcomes. While we are not yet able to cure MS, being able to realise NEDA may be a significant step forward clinically and these effects carry forward to societal benefits by keeping people with MS in the workforce. This has the benefit of allowing people with MS to continue as productive citizens and results, showing $26 \%$ reduction in loss of not relying on disability pension supports, which is of economic and societal benefit. Beyond this, though, continuing to be productive and capable citizens is of psychological benefit for the people themselves, enhancing their quality of life and facilitating a positive feedback on their overall health.

\section{Contributors SS wrote the editorial.}

Funding The author has not declared a specific grant for this research from any funding agency in the public, commercial or not-for-profit sectors.

\section{Competing interests None declared.}

Patient consent for publication Not required.

Provenance and peer review Commissioned; internally peer reviewed.

(c) Author(s) (or their employer(s)) 2020. No commercial re-use. See rights and permissions. Published by BMJ.

$$
\text { A) Check for updates }
$$

To cite Simpson, Jr. S. J Neurol Neurosurg Psychiatry 2020;91:6.

Received 28 October 2019

Revised 31 October 2019

Accepted 1 November 2019

Published Online First 14 November 2019

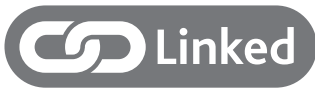

- http://dx.doi.org/10.1136/jnnp-2019-321523

J Neurol Neurosurg Psychiatry 2020;91:6. doi:10.1136/jnnp-2019-321761

\section{ORCID iD}

Steve Simpson, Jr. http://orcid.org/0000-0001-65213056

\section{REFERENCES}

1 Krause I, Kern S, Horntrich A, et al. Employment status in multiple sclerosis: impact of diseasespecific and non-disease-specific factors. Mult Scler 2013;19:1792-9.

2 Wingerchuk DM, Carter JL. Multiple sclerosis: current and emerging disease-modifying therapies and treatment strategies. Mayo Clin Proc 2014;89:225-40.

3 Giovannoni G. Disease-Modifying treatments for early and advanced multiple sclerosis: a new treatment paradigm. Curr Opin Neurol 2018;31:233-43.

4 Chalmer TA, Buron M, Illes Z, et al. Clinically stable disease is associated with a lowerrisk of both income loss and disability pension forpatients with multiple sclerosis. J Neurol Neurosurg Psych 2019:1-8.

5 Yamout B, Issa Z, Herlopian A, et al. Predictors of quality of life among multiple sclerosis patients: a comprehensive analysis. Eur J Neurol 2013;20:756-64. 